\title{
Kyllinga (Cyperaceae) do estado de Sergipe, Brasil
}

\author{
Kyllinga (Cyperaceae) in Sergipe state, Brazil
}

\author{
Suzana Maria Costa ${ }^{1,4}$, Ana Paula Prata $^{2} \&$ Marccus Alves $^{3}$
}

\begin{abstract}
Resumo
Kyllinga Rottb. possui cerca de 50 espécies distribuídas na América e África tropical, região onde apresenta maior riqueza. Seis espécies possuem material testemunho confirmando sua ocorrência para o Brasil, mas levantamentos florísticos e estudos taxonômicos que englobem plantas de hábito herbáceo são escassos em Sergipe, sendo o número real de espécies de Kyllinga incerto para o estado. Esse estudo foi elaborado visando realizar o levantamento das espécies do gênero ocorrentes no território sergipano. Foram realizadas coletas em diferentes regiões de Sergipe e, a partir do material recém-coletado e aquele depositado em herbários da região, foi confirmada a ocorrência de seis espécies de Kyllinga para o estado sendo três destas novas ocorrências, nos domínios da Mata Atlântica e Caatinga. Esse estudo também provê material necessário para a identificação das espécies: chave de identificação de espécies, descrições e ilustrações.

Palavras-chave: Caatinga, Mata Atlântica, ruderais, taxonomia.
\end{abstract}

\begin{abstract}
Kyllinga Rottb. owns approximately 50 species distributed in America and tropical Africa, where most of them occurs. Six species has vouchers confirming its occurrence in Brazil, but floristic and taxonomic studies are scarce in Sergipe, maintaining the real number of Kyllinga uncertain. This study was elaborated aiming the inventory of species in Sergipe's territory. Expeditions were done in different regions of Sergipe and, based on these recent collected material and those deposited in regional herbaria, six species of Kyllinga was confirmed to Sergipe, three of them new occurrences, in Atlantic Forest and Caatinga domains. This study also provides the necessary material to identification of species: identification keys, descriptions and illustrations.
\end{abstract} Key words: Caatinga, Atlantic Forest, ruderals, taxonomy.

\section{Introdução}

Kyllinga Rottb. possui cerca de 50 spp. distribuídas na América e África Tropical, onde apresenta maior riqueza (Tucker 1998). Para o Brasil há ocorrência confirmada de seis espécies (Alves et al. 2009).

A qualificação de Kyllinga como gênero ou subgênero ainda é controversa. Estudos filogenéticos realizados em Cyperaceae (Muasya et al. 2001, 2009a, 2009b) vêm apontando a necessidade de junção de Cyperus s.s. com gêneros próximos, incluindo Kyllinga, para que o mesmo se torne um táxon monofilético
(Muasya et al. 2001, 2009b). Entretanto para que mudanças taxonômicas sejam realizadas há necessidade de maior amostragem do clado Cyperus nas análises filogenéticas da família (Muasya et al. 2009b).

Poucos estudos florísticos foram realizados em Sergipe e estes não se atêm, ou tratam apenas superficialmente, de indivíduos herbáceos (Souza 1983; Fonseca 1991; Vicente et al. 2005; Mendes et al. 2010). O presente estudo foi realizado objetivando o levantamento das espécies de Kyllinga Rottb. no Estado de Sergipe, fornecendo dados para a identificação das mesmas.

\footnotetext{
${ }^{1}$ Universidade Estadual de Campinas, Instituto de Biologia, Cidade Universitária Zeferino Vaz, Rua Monteiro Lobato 255, 13083-862, Campinas, SP, Brasil.

${ }^{2}$ Universidade Federal de Sergipe, Dept.o de Biologia, Campus Universitário Professor Aloísio de Campos, 49100-000, São Cristóvão, SE, Brasil.

${ }^{3}$ Universidade Federal de Pernambuco, Av. Moraes Rego s/n, 51670-930, Recife, PE, Brasil.

${ }^{4}$ Autora para correspondência: suzanamscosta@yahoo.com.br
} 


\section{Materiais e Métodos}

O estado de Sergipe possui extensão territorial de $21.910,348 \mathrm{~km}^{2}$ e está localizado na Região Nordeste do Brasil. Em seu território apresenta diversas fitofisionomias inseridas nos domínios da Mata Atlântica e Caatinga, havendo entre os dois domínios uma faixa ecotonal de características mistas em composição e estrutura da vegetação. Devido ao histórico de modificação para exploração agropecuária, são poucas as áreas de vegetação primária no estado, existindo apenas quinze Unidades de Conservação da Natureza concentradas na região leste do estado no domínio da Mata Atlântica (Gomes et al. 2006; Silva \& Souza 2009; SEMARH 2012)

Coletas foram realizadas no período entre abril de 2006 e março de 2009. As coletas foram realizadas em todas as regiões do estado e nelas foram amostrados fragmentos vegetacionais nos domínios da Mata Atlântica e Caatinga, assim como a área de ecótono existente entre os mesmos. Foram incluídas áreas com físionomia variando entre florestada e graminosa em diferentes condições de preservação em estações do ano distintas. Áreas verdes urbanas, embora claramente modificadas, foram incluídas devido ao caráter ruderal atribuído às espécies do gênero (Adams 1994; Luceño et al. 1997; Alves et al. 2009).

O material coletado foi herborizado seguindo métodos descritos por Mori et al. (1989) e Liesner (2002) e incorporado ao acervo do Herbário ASE (Universidade Federal de Sergipe). Paralelamente ao período das coletas, foram visitados os acervos de alguns herbários da Região Nordeste (HUEFS, HX e UFP), mas na ocasião estes não possuíam representantes do gênero coletados em Sergipe.

A chave de identificação, descrições sucintas, ilustrações de aspectos importantes (incluindo os cortes transversais dos escapos à mão-livre) e informações sobre habitat de cada espécie são baseadas em material recém-coletado e depositado nos herbários. A descrição do gênero se baseia tanto no material coletado quanto em literatura especializada (Adams 1994; Luceño et al. 1997). A sinonímia aceita para os táxons é aquela apresentada em Alves et al. (2009). A distribuição geográfica das espécies no globo é apresentada de acordo com Luceño et al. (1997) e, devido à necessidade de refinamento dos dados apresentados em Alves et al. (2012), a distribuição adotada para as espécies de Kyllinga no Brasil são aquelas apresentadas em Alves et al. (2009).
Após o tratamento de cada espécie é disponibilizada uma lista de material selecionado analisado, contendo um exemplar para cada município do estado, em ordem alfabética, onde a espécie foi registrada, preferencialmente exsicatas com estruturas vegetativas e reprodutivas completas.

\section{Resultados e Discussão}

Após a realização de coletas e análise de exemplares depositados nos herbários visitados, todas as seis espécies de Kyllinga Rottb. confirmadas para o Brasil ocorrem em Sergipe, sendo que três destas são novas ocorrências "para o estado" (destacadas com *): K. brevifolia Rottb.*, K. nemoralis (J.R. Forst. \& G. Forst) Dandy ex Hutch.*, K. odorata Vahl, K. pumila Michx.*, K. squamulata Vahl e K. vaginata Lam. As espécies foram registradas principalmente em áreas pertencentes aos domínios da Mata Atlântica, além da Caatinga, e na região de ecótono entre ambos os domínios.

As espécies ocorreram em ambientes antropizados, seja em fragmentos dentro de perímetro urbano, onde a modificação é mais evidente, ou áreas adjacentes a trilhas em fragmentos de vegetação original de Sergipe. Em locais mais preservados, tanto em fisionomia florestal quanto campestre dentro do gradiente vegetacional Mata Atlântica-Caatinga existente, o gênero não foi encontrado. Essa situação corrobora o caráter ruderal frequentemente atribuído à Kyllinga (Adams 1994; Luceño et al. 1997; Alves et al. 2009).

Dentre as espécies citadas para o país em Alves et al. (2009) apenas $K$. tibialis Ledeb. não possui registro para o território sergipano. Embora esta espécie tenha sido citada para o Brasil não foi encontrado material testemunho que comprovasse sua ocorrência em território nacional (Alves et al. 2009).

\section{Kyllinga Rottb.}

Plantas herbáceas, rizomatosas ou cespitosas, até $50 \mathrm{~cm}$ alt., apresentando raízes aromáticas. Rizoma, quando presente, horizontal, recoberto por escamas canaliculadas. Folhas apresentando somente bainhas ou com lâminas desenvolvidas; bainha canaliculada, glabra; lâminas lineares, 1-4 mm larg., escabras nas margens e face abaxial da nervura central, ápice acuminado. Escapo ereto, trígono a irregularmente cilíndrico, glabro. Brácteas involucrais 2-4, foliáceas, apresentando larguras similares a lâmina foliar, com comprimentos iguais ou não entre si, escabras 
nas margens e face abaxial da nervura central. Inflorescência em espiga terminal, 1-4(5) espigas secundárias, menores que a principal; ráquis oculto pelas espiguetas densamente dispostas em espiral. Espigueta uniflora ou, raramente, biflora, caducas na maturidade. Glumas precedidas por bráctea inconspícua e profilo. Glumas 2, raramente três (na espigueta biflora), dísticas, naviculares, carenadas de ápice mucronado; carena lisa ou escabra, alada ou não. Flores 1-2 estames, estigma bífido. Aquênio até 1,5 mm compr., lenticular, obovado, circular ou elíptico, verde no estágio imaturo.

\section{Chave de identificação para espécies de Kyllinga Rottb. do estado de Sergipe}

1. Espiguetas com glumas aladas

2. Plantas rizomatosas; inflorescência branca; espiguetas simétrica ou assimetricamente obovadas, glumas com alas restritas à porção mediana e apical da carena. 2. K. nemoralis

2'. Plantas cespitosas; inflorescência esverdeada; espiguetas lanceoladas a ovais, glumas com alas irregulares por todo comprimento da carena.

5. K. squamulata

1'. Espiguetas com glumas não aladas

3. Plantas cespitosas ou rizomatosas com entrenós inconspícuos

4. Inflorescência branca; ráquis com ápice agudo; glumas com carena lisa 3. K. odorata

4'. Inflorescência esverdeada; ráquis com ápice truncado; glumas com carena escabra

4. K. pumila

3'. Plantas rizomatosas com entrenós evidentes

5. Plantas com folhas de lâminas sempre desenvolvidas; brácteas com comprimentos desiguais; bráctea inferior ereta, mais comprida que as demais e assemelhando-se a continuação do escapo. 1. K. brevifolia

5'. Plantas com folhas geralmente reduzidas à bainha; brácteas com comprimentos semelhantes, sem essa combinação de caracteres. 6. K. vaginata

1. Kyllinga brevifolia Rottb., Descr. Icon. Rar. Pl. 13. 1773.

Fig 1a-d

Erva, $15-40 \mathrm{~cm}$ alt. Rizoma 2-3 mm larg. Bainha foliar 2-6 cm compr., recobrindo $1 / 5$ do escapo; lâmina foliar 4-10 × 0,1-0,2 cm. Escapo $8-40 \times 0,1 \mathrm{~cm}$, trígono. Brácteas involucrais 3-4, 5-10 cm compr., desiguais em comprimento; bráctea inferior às vezes mais longa e ereta. Espiga globosa, 3-6 mm diâm., ca. 50 espiguetas, verde; quando presentes, espigas laterais inconspícuas. Ráquis cônico, $0,5-0,8 \mathrm{~mm}$ diâm. na base, pedicelo presente. Espigueta uniflora, $2-3 \times 1$ $\mathrm{mm}$, lanceolada. Glumas 2, 2-3 $\times 2 \mathrm{~mm}$, elíptica a lanceolada, 6 linhas submargnais longitudinais; carena escabra, 5-8 acúleos. 1-2 estames. Aquênio $1-1,3 \times 0,5-0,7 \mathrm{~mm}$, obovóide, preto.

Material examinado: Aracaju, 23.VIII.2007, fl. e fr., A.C. Silva et al. 126 (ASE). Itaporanga d'Ajuda, 9.XI.2008, fl. e fr., S.M. Costa 261 (ASE). São Cristóvão, 10.VII.2006, fl. e fr., S.M. Costa 30 (ASE).

Kyllinga brevifolia apresenta distribuição Pantropical (Luceño et al. 1997). Em Sergipe, é encontrada no domínio da Mata Atlântica, em áreas de Restinga (solo arenoso) e na transição entre Restinga e Manguezal (solo encharcado, lamacento e escuro), em diferentes níveis de antropização. Difere das demais espécies de hábito rizomatoso por possuir espiga globosa, verde e geralmente única.

2. Kyllinga nemoralis (J.R. Forster \& G. Forster) Dandy ex Hutchinson \& Dalziel, Fl. W. Trop. Afr. 2: 487.1936.

Fig 1e-i

Erva, até $10 \mathrm{~cm}$ alt. Rizoma ca. $3 \mathrm{~mm}$ larg. Bainha foliar $0,5-1 \mathrm{~cm}$, recobrindo $1 / 6-1 / 5$ do escapo; lâmina foliar 2-10 × 0,2 cm. Escapo 3-4 $\times 0,1 \mathrm{~cm}$, trígono. Brácteas involucrais $3-4,1-4$ $\mathrm{cm}$ compr., iguais em comprimento. Espiga oval, ca. $7 \times 5$ mm diâm., ca. 100 espiguetas, branca. Ráquis cônico, ca. $3 \mathrm{~mm}$ diâm. na base, pedicelo ausente. Espigueta uniflora, 2,5-3 × 1-1,5 mm, oboval a assimetricamente oboval. Glumas 2, 2,5-3 $\times 1,5 \mathrm{~mm}$, elíptica a oboval, 6 linhas submarginais longitudinais; carena alada, alas de margem regular e escabra, 8-14 acúleos. 2 estames. Aquênio 1-1,5 $\times$ 0,5-0,7 mm, elípsóide, marrom.

Material selecionado: Aracaju, 29.X.2007, fl. e fr., S.M. Costa 171 (ASE). 


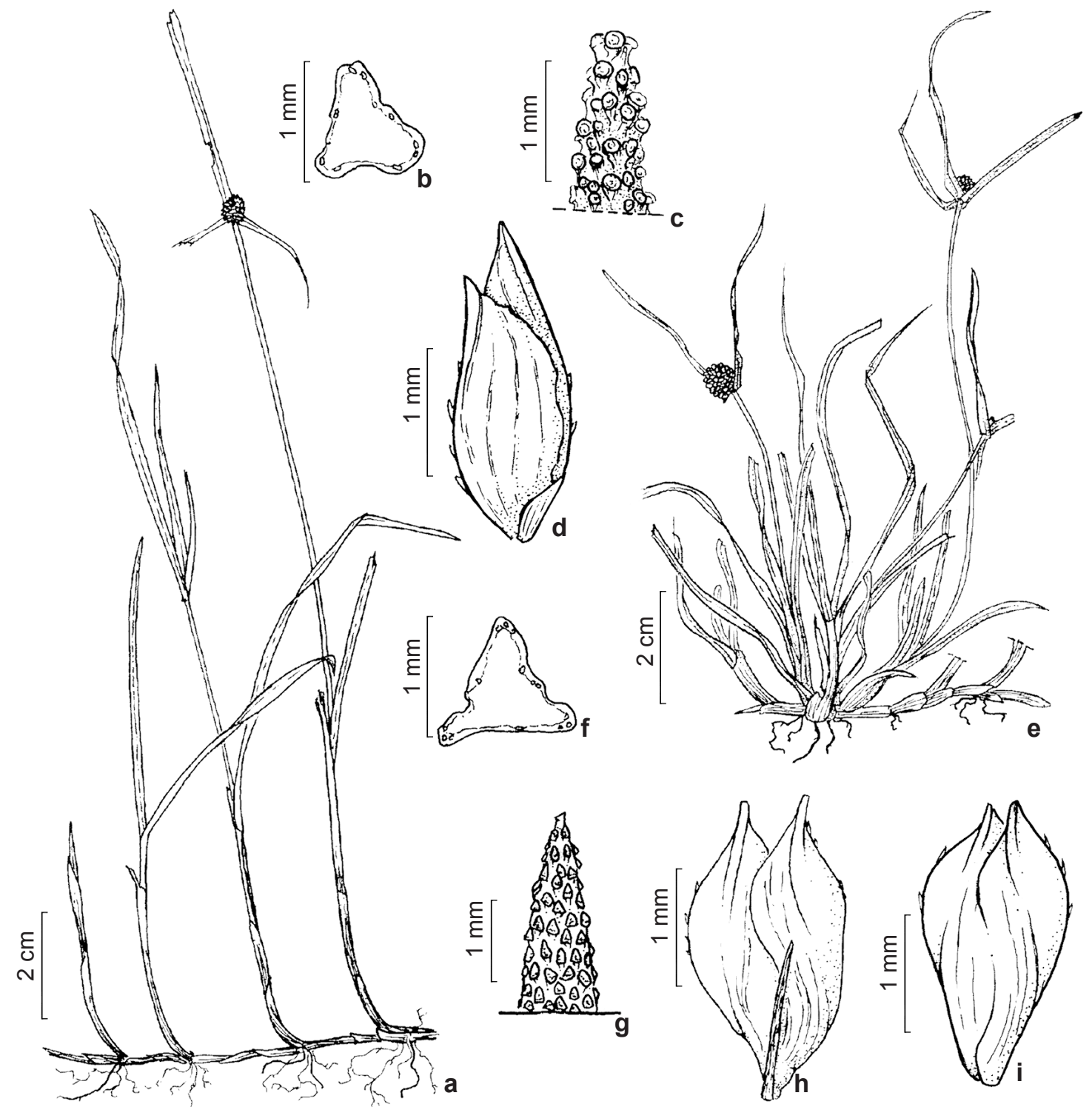

Figura 1 - Kyllinga brevifolia Rottb. - a. hábito; b. corte transversal do escapo; c. ráquis; d. espigueta (S.M. Costa 30). Kyllinga nemoralis (J.R.Forst. \& G.Forst.) Dandy ex Hutch. - e. hábito; f. corte transversal do escapo; g. ráquis; h. espigueta assimétrica; i. espigueta simétrica (S.M. Costa 171).

Figure 1 - Kyllinga brevifolia Rottb. - a. habit; b. transversal section of culm; c. rachis; d. spikelet (S.M. Costa 30). Kyllinga nemoralis (J.R. Forst. \& G.Forst.) Dandy ex Hutch. - e. habit; f. tranversal section of culm; g. rachis; h. assimetric spikelet; i. simetric spikelet (S.M. Costa 171).

Kyllinga nemoralis ocorre nos trópicos do Velho Mundo e foi provavelmente introduzida na América (Luceño et al. 1997). Em Sergipe ocorre somente em áreas verdes urbanas. Diferencia-se das outras espécies rizomatosas pelo formato oboval simétrico ou assimétrico de sua espigueta, derivado do posicionamento apical das alas nas glumas. Além de K. nemoralis, apenas K. squamulata possui glumas aladas, mas esta espécie apresenta hábito cespitoso.
3. Kyllinga odorata Vahl, Enum. P1. 2: 382. 1805.

Fig 2a-e

Erva, $10-45 \mathrm{~cm}$ alt. Bainha foliar $0,5-10 \mathrm{~cm}$, recobrindo ca. 1/5 do escapo; lâmina foliar 5-30 $\times 0,3 \mathrm{~cm}$. Escapo 10-45 × 0,1-0,3 cm, trígono. Brácteas involucrais 2-5(6), 5-20 cm compr., desiguais em comprimento. Espiga globosa a oblongo-cilíndrica, 5-20 $\times 7 \mathrm{~mm}$, ca. 200 espiguetas, alva; espigas laterais $1-4$, até $7 \mathrm{~mm}$ compr., 
menores que a principal. Ráquis cilíndrico, ca. 0,8 mm diâm. na base, pedicelo ausente. Espigueta uniflora ou biflora. Espigueta uniflora, 2,5-3 × 1 $\mathrm{mm}$, lanceolada. Glumas 2, 2,5-3 × $2 \mathrm{~mm}$, oboval a lanceolada, 4-6 linhas submarginais longitudinais; carena lisa. Espigueta biflora, ca. $3 \times 2 \mathrm{~mm}$, oval. Glumas 3, 2,5-3 × $1 \mathrm{~mm}$, oboval a lanceolada, ca. 8 linhas submarginais longitudinais; carena lisa. 2 estames. Aquênio ca. $1 \times 1 \mathrm{~mm}$, obovóide, preto.

Material examinado: Aracaju, 15.VI.2007, fl. e fr., S.M. Costa 148 (ASE). Areia Branca, 20.IX.2008, fl. e fr., S.M. Costa et al. 459 (ASE). Cedro de São João, 7.VIII.2010, fl. e fr., I.R.N. Menezes et al. 118 (ASE). Itabaiana, 15.IX.2006, fl. e fr., S.M. Costa et al. 123 (ASE). Itaporanga d'Ajuda, 9.I.2008, fl. e fr., S.M. Costa 246 (ASE). Riachão do Dantas, 17.VI.1982, fl. e fr., E. Gomes 67 (ASE). Salgado, 24.VII.1982, fl. e fr., G. Viana 567 (ASE). Santa Luzia do Itanhy, 28.VI.2011, fl. e fr., L.A. Gomes et al. 167 (ASE). São Cristóvão, 23.VI.2006, fl. e fr., S.M. Costa 15 (ASE).

Kyllinga odorata apresenta distribuição Pantropical (Adams 1994; Luceño et al. 1997). Em Sergipe é encontrada nos domínios da Mata Atlântica e Caatinga, em áreas antropizadas. Distingue-se das demais espécies por possuir espigas geralmente cilíndricas, alvas e por suas glumas de carena lisa e sem alas.

No material analisado houve formação de aquênio na flor apical morfologicamente similar ao da flor basal e de uma gluma adicional (Trevisan et al. 2007). Três espécimes (ASE 8749, ASE 9187, ASE 10731) apresentaram uma ramificação no escapo, estrutura incomum na tribo Cypereae. Essa ramificação parte de diferentes alturas do escapo e, embora não apresente brácteas involucrais, desenvolve espiguetas com flores e aquênios morfologicamente normais.

4. Kyllinga pumila Michx., F1. bor-amer. 1: 28. 1803.

Fig. $2 \mathrm{f}-\mathrm{i}$

Erva, 20-50 cm alt. Bainha foliar $3-8 \mathrm{~cm}$ compr., recobrindo 1/5-1/3 do escapo; lâmina foliar 3-15 × 0,3 cm. Escapo 10-25 × 0,1 cm, trígono. Brácteas involucrais 3-4, 2-15 cm compr. Espiga oval a globosa, ca. $5 \times 5 \mathrm{~mm}$, verde, ca. 150 espiguetas; espigas laterais 1-2, 1-2 × 1-2 mm. Ráquis cilíndrico, ca. $1 \mathrm{~mm}$ diâm. na base, pedicelo presente. Espigueta uniflora, ca. $3 \times 1 \mathrm{~mm}$, lanceolada a elíptica. Glumas 2 , ca. $3 \times 1 \mathrm{~mm}$, oboval a lanceolada, ca. 8 linhas submarginais longitudinais; carena escabra, 7-8 acúleos. 2 estames. Aquênio ca. $1 \times 0,7 \mathrm{~mm}$, oblongoobovóide, verde-amarelado quando imaturo.

Material examinado: Capela, 15.VI.2007, fl. e fr., A.C. Silva \& K.C.S. Teixeira 80 (ASE). Itabaiana, 15.IX.2006, fl. e fr., S.M. Costa et al. 120 (ASE)
Kyllinga pumila ocorre nos trópicos e subtrópicos da África e América (Luceño et al. 1997). Em Sergipe, foi encontrada no domínio da Mata Atlântica, em fragmento antropizado de mata. Diferencia-se de $K$. brevifolia, espécie com a qual pode ser confundida, por suas glumas densamente escabras e hábito cespitoso.

5. Kyllinga squamulata Thonn ex Vahl, Enum. Pl. 2: 381.1805.

Fig. 3a-d

Erva, ca. $30 \mathrm{~cm}$ alt. Bainha foliar até $4 \mathrm{~cm}$ compr., recobrindo ca. 1/3-1/5 do escapo; lâmina foliar 3-15 × 0,2 cm. Escapo 4-20 × 0,1 cm, irregularmente cilíndrico. Brácteas involucrais 3-4, 3-10 cm compr. Espiga globosa a oval, ca. $5 \times 5 \mathrm{~mm}$, 40-60 espiguetas; espiga secundária inconspícua. Ráquis cônico, ca. $1 \mathrm{~mm}$ diâm. na base, pedicelo presente. Espigueta uniflora, ca. 3-4 × 3-4 mm, lanceolada ou oval. Glumas 2, 3-4 × 1,5-2 mm, oval-lanceolada; carena alada, alas com margem irregular, 6-12 acúleos. 2 estames. Aquênio ca. 1,5 $\times 1,5 \mathrm{~mm}$, ovóide a circular, castanho.

Material examinado: Aracaju, 17.VIII.2007, fl. e fr., S.M. Costa et al. 163 (ASE). Poço Redondo, 26.VIII.2006, fr. e fl., A.P. Prata et al. 1334 (ASE). Santa Luzia do Itanhy, 9.IX.2011, fl. e fr. A.P. Prata et al. 2708 (ASE). São Cristóvão, 31.V.2006, fl. e fr., I.C. Lemos \& S.M. Costa 2 (ASE).

Kyllinga squamulata distribui-se pelos trópicos do Velho Mundo, de onde é nativa, e é considerada introduzida na América, ocorrendo na Flórida, algumas ilhas do Caribe e Brasil (Luceño et al. 1997). Em Sergipe é encontrada em solo úmido em áreas de Caatinga e Mata Atlântica antropizadas. É facilmente identificável pelas alas irregulares de suas espiguetas visíveis a olho nu.

\section{Kyllinga vaginata Encycl. 1: 148. 1791.}

Fig. 3e-h

Erva, 10-40 cm alt. Rizoma 0,3-0,5 cm de larg. Folha geralmente apresentando apenas bainha; bainha foliar 1-9 cm compr., recobrindo 1/7-1/4 do escapo; lâmina foliar $1-5 \times 0,2-0,4$ $\mathrm{cm}$. Escapo 5-40 × 0,1-0,2 cm, trígono. Brácteas involucrais 2-4, 1-4 cm compr. Espiga globosa a oval, $0,5-1,3 \times 0,3-0,7 \mathrm{~cm}, 50-250$ espiguetas; às vezes com espigas laterais, até $5 \mathrm{~mm}$ compr. Ráquis cônico, 1-2 mm diâm. na base, pedicelo presente. Espigueta uniflora, 2-3 $\times 1 \mathrm{~mm}$, lanceolada a elíptica. Glumas 2, 2-3 × $2 \mathrm{~mm}$, oboval, ca. 6-8 linhas submarginais longitudinais; carena (0)2-6 acúleos. 2 estames. Aquênio ca. $1 \times 0,5 \mathrm{~mm}$, obovóide a oblongo, enegrecido. 


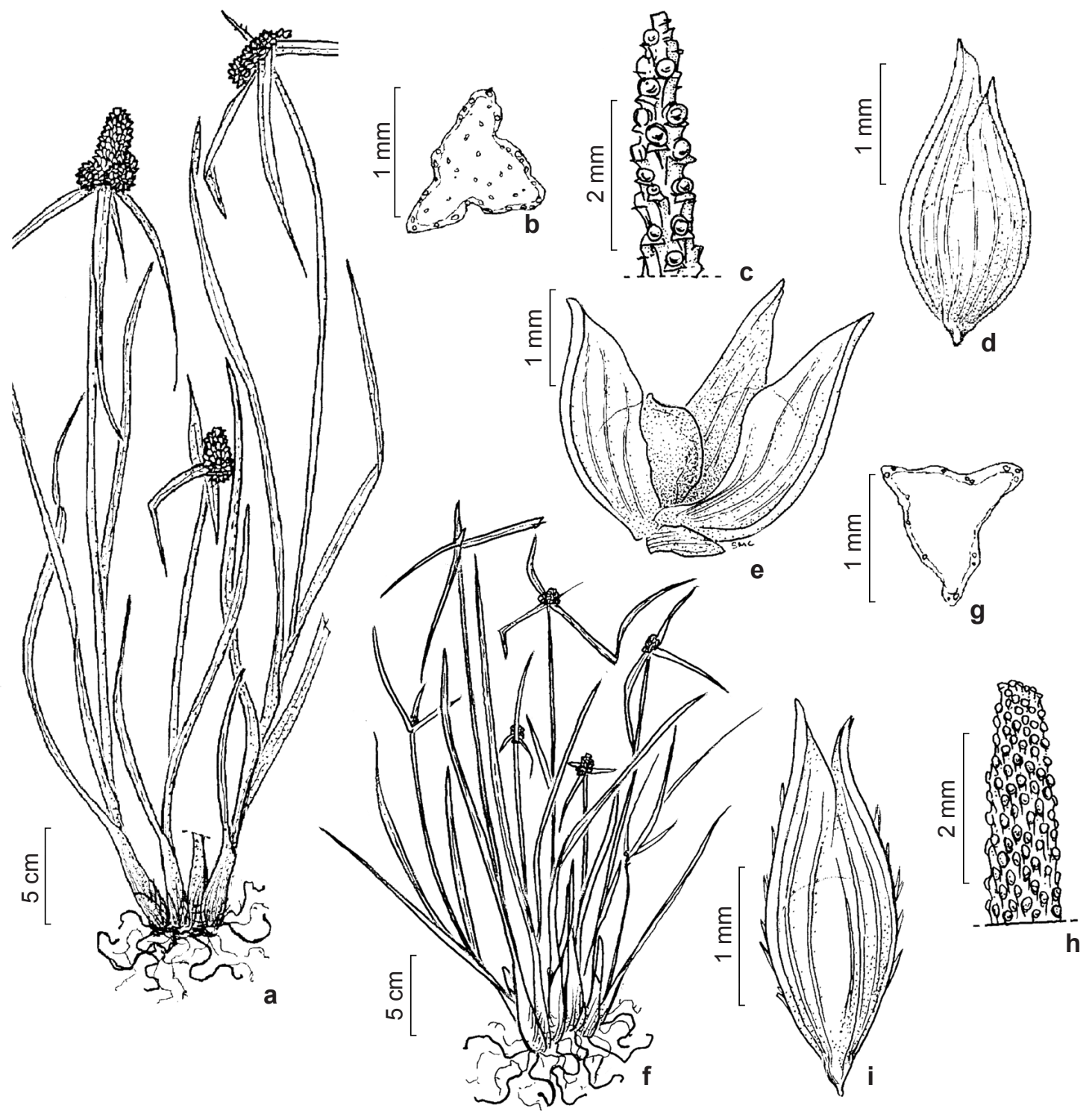

Figura 2 - Kyllinga odorata Vahl - a. hábito; b. corte transversal do escapo; c. ráquis; d. espigueta uniflora; e. espigueta biflora (a-c. E. Gomes 67, d-e. S.M. Costa 10). Kyllinga pumila Michx. - f. hábito; g. corte transversal do escapo; h. ráquis; i. espigueta (S.M. Costa 120).

Figure 2 - Kyllinga odorata Vahl - a. habit; b. transversal section of culm; c. rachis; d. flowered spikelet; e. flowered spikelet (a-c. E.Gomes 67, d-e. S.M. Costa 10). Kyllinga pumila Michx. -f. habit; g. transversal section of culm; h. rachis; i. spikelet (S.M. Costa 120).

Material examinado: Aracaju, 17.VII.2007, fl. e. fr., S.M. Costa et al. 157 (ASE). Areia Branca, 27.XI.2007, fl. e. fr., S.M. Costa \& J.E. Nascimento Júnior 178 (ASE). Barra dos Coqueiros, 18.XII.2008, fl. e. fr., J.E. Nascimento Júnior \& T.V.P. Dantas 428 (ASE). Estância, 8.X.1993, fl. e. fr., J.G. Jardim et al. 318 (ASE). Itabaiana, 14.IV.1991, fl. e. fr., M.L. Santos 86 (ASE). Itaporanga d'Ajuda, 9.I.2008, fl. e. fr., S.M. Costa 247 (ASE). Pirambu, 3.IV.2006, fl. e. fr., S.M. Costa et al. 2 (ASE). São Cristóvão, 15.II.2008, fl. e. fr., S.M. Costa \& C. Calazans 301 (ASE).
Kyllinga vaginata distribui-se pela América Central e regiões tropicais e temperadas da América do Sul (Adams 1994; Luceño et al. 1997). Em Sergipe, foi encontrada em áreas de restinga e mata ciliar no domínio da Mata Atlântica e na região de ecótono entre os domínios de Mata Atlântica e Caatinga. Distingue-se das demais espécies por apresentar hábito rizomatoso e por possuir folhas, em geral, somente com bainhas. 


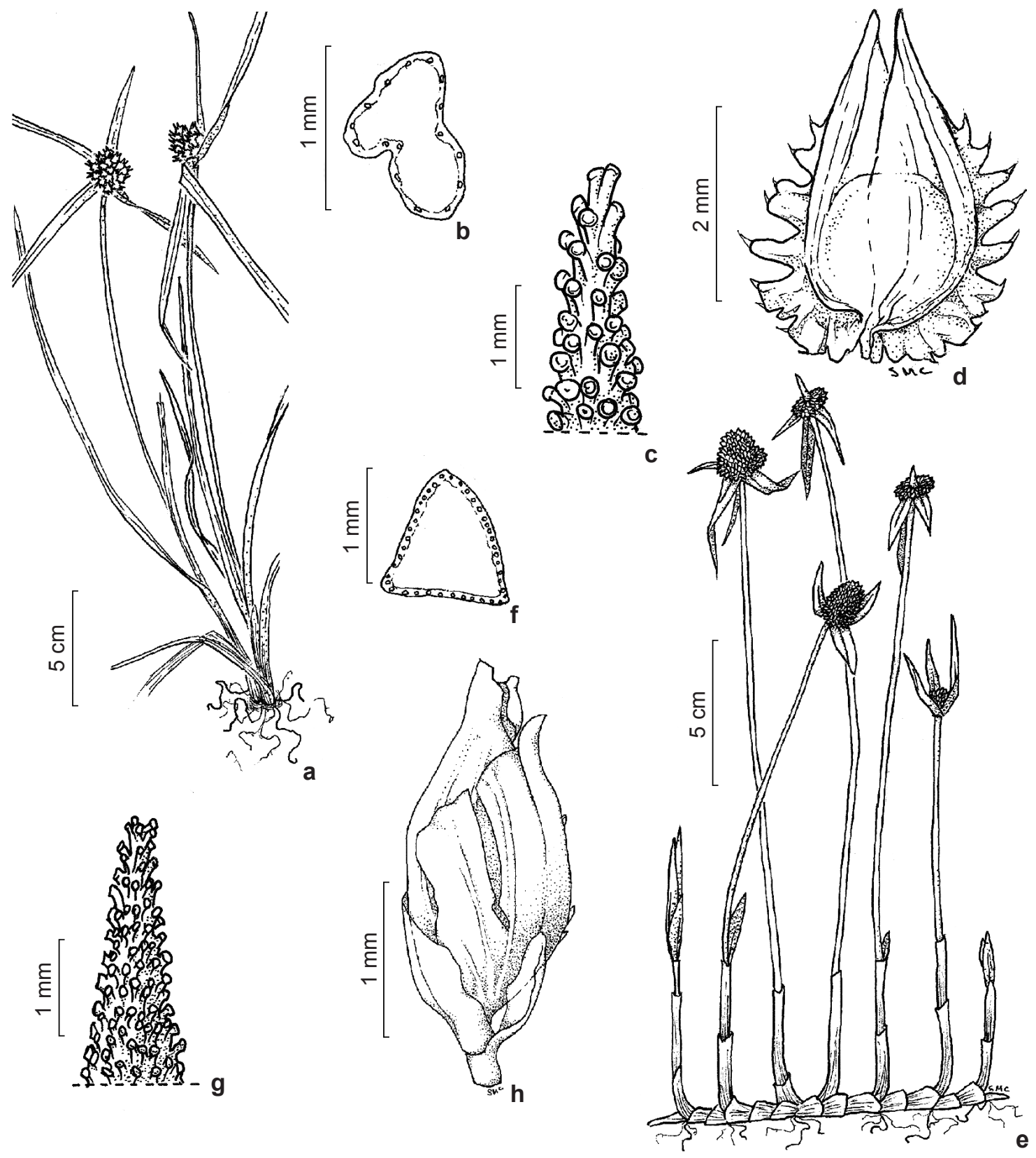

Figura 3 - Kyllinga squamulata Vahl - a. hábito; b. corte transversal do escapo; c. ráquis; d. espigueta (S.M. Costa 163). Kyllinga vaginata Lam. - e. hábito; f. corte transversal do escapo; g. ráquis; h. espigueta (M. Ramos 2).

Figura 3 - Kyllinga squamulata Vahl - a. habit; b. transversal section of culm; c. rachis; d. spikelet (S.M. Costa 163). Kyllinga vaginata Lam. - e. habit; f. transversal section of culm; g. rachis; h. spikelet (M. Ramos 2).

Em Cyperaceae, a identificação da maioria das espécies só é possível com a análise de aquênios maduros. Os aquênios de Kyllinga, diferente daqueles de outros gêneros da família, não apresentam características que favoreçam a identificação em nível de espécie (Oliveira 1980; Ferreira \& Eggers
2008). Durante o presente trabalho a utilização de características da espigueta (forma, presença/ ausência de alas e acúleos) e do ráquis (forma do ráquis e desenvolvimento e organização dos pedúnculos) foram mais úteis nessa identificação. Tanto em espécimes cujas inflorescências encontravam-se 
imaturas (características da espigueta) quanto em espécimes cujas espiguetas não estavam disponíveis (características do ráquis).

A variação do formato da ráquis dessas espécies demonstra a importância de características desta estrutura para a identificação das mesmas. Uma análise dessa variação em outros integrantes da tribo Cypereae é necessária para que o uso desse caráter possa ser aplicado na identificação de outras espécies dessa ou de outras tribos (em espécies cujos exemplares não estejam em fase de frutificação ou os aquênios não apresentem caracteres suficientes para a determinação da mesma).

\section{Agradecimentos}

Este trabalho faz parte do projeto de pesquisa "Estudos Forísticos e taxonômicos das Cyperaceae de Sergipe Brasil", coordenado pela Prof ${ }^{\mathrm{a}} \mathrm{Dr}^{\mathrm{a}}$ Ana Paula Prata e traz parte dos resultados obtidos durante a bolsa IC (PIBIC,CNPq) recebida pela primeira autora.

\section{Referências}

Adams, C.D. 1994. Kyllinga Rottb. (Cyperaceae). In: Davidse, G.; Sousa, M.S.; Chater, A.O. (eds.). Flora Mesoamericana - Alismataceae a Cyperaceae. Universidad Nacional Autónoma de México. Missouri Botanical Garden, The Natural History Museum (London). Vol. 6. Pp. 402-501.

Alves, M.; Araujo, A.C.; Hefler, S.M.; Trevisan, R.; Silveira, G.H.; Luz, C.L. 2012. Cyperaceae In: Forzza, R.C. et al. (eds.). Lista de espécies da flora do Brasil. Jardim Botânico do Rio de Janeiro. Disponível em: < http://floradobrasil.jbrj.gov.br/2012/FB000100>. Acesso em 29 Jan 2012.

Ferreira, P.M.A. \& Eggers, L. 2008. Espécies de Cyperaceae do Centro de Pesquisa e Conservação da Natureza Pró-Mata, município de São Francisco de Paula, RS, Brasil. Acta Botanica Brasilica 22: 173-185.

Fonseca, M.R. 1991. Análise da vegetação arbustivoarbórea da caatinga hiperxerófila do noroeste do estado de Sergipe. Tese de Doutorado. Universidade Estadual de Campinas, Campinas. 187p.

Gomes, L.J.; Santana, V. \& Ribeiro, G.T. 2006. Unidades de Conservação no estado de Sergipe. Revista da Fapese 2: 101-112.

Liesner, R. 2002. Field techniques used by Missouri Botanical Garden. Disponível em: <www.mobot. org > . Acesso em 15 Abr 2006.

Luceño, M.; Alves, M.V. \& Mendes, A.P. 1997. Catálogo florístico y claves de identificación de las ciperáceas de los estados de Paraíba e Pernambuco (Nordeste do Brasil). Anales del Jardín Botánico de Madrid 57: 67-100.

Mendes, K.; Gomes, P. \& Alves, M. 2010. Inventário florístico de uma área de tensão ecológica na Mata Atlântica do Nordeste do Brasil. Rodriguésia 61: 669-676.

Mori, S.; Silva, L.; Lisboa, G. \& Coradin, L. 1989. Manual de manejo do herbário fanerogâmico. CEPLAC - Comissão Executiva de Planejamento da Lavoura Cacaueira, Ilhéus. 103p.

Muasya, A.M.; Simpson, D.A. \& Chase, M.W. 2001. Generic relationships and character evolution in Cyperus s.l. (Cyperaceae). Systematics and Geography of Plants 71: 539-544.

Muasya, A.M.; Simpson, D.A.; Verboom, G.A.; Goetghebeur, P.; Naczi, R.F.C.; Chase, M.W. \& Smets, E. 2009a. Phylogeny of Cyperaceae based on DNA sequence data: current progress and future prospects. Botanical Review 75: 2-21.

Muasya, A.M.; Vrijdaghs, A.; Simpson, D.A.; Chase, M.W.; Goetghebeur, P. \& Smets, E. 2009b. What is a genus in Cypereae: phylogeny, character homology assessment and generic circumscription in Cypereae. Botanical Review 75: 52-66.

Oliveira, E.C. 1980. Cyperaceae Juss. - morfologia dos aquênios de gêneros ocorrentes no Brasil. Rodriguésia 31: 327-405.

SEMARH (Secretaria de Estado do Meio Ambiente e dos Recursos Hídricos), 2012. Áreas protegidas, biodiversidade e florestas. Disponível em: $<\mathrm{http} / /$ www.semarh.se.gov.br/biodiversidade/modules/ tinyd0/index.php?id=11>. Acesso em 6 Jan 2012.

Silva, M.S.F. \& Souza, R.M. 2009. O potencial fitogeográfico de Sergipe: uma abordagem a partir das unidades de conservação de uso sustentável. Scientia Plena 5: 1-10.

Souza, G.V. 1983. Estrutura da vegetação da Caatinga hipoxerófila do estado de Sergipe. Dissertação de Mestrado. Universidade Federal Rural de Pernambuco, Recife. 95p.

Trevisan, R.; Lüdtke, R. \& Boldrini, I.I. 2007. O gênero Kyllinga Rottb. (Cyperaceae) no Rio Grande do Sul, Brasil. Revista Brasileira de Biociências 5: 27-36.

Tucker, G.C. 1998. Kyllinga Rottb. In: Berry, P.E.; Holst, B.K. \& Yatskievych, K. (eds.). Flora of the Venezuelan Guayana. Caesalpiniaceae-Ericaceae. Vol. 4. Missouri Botanical Garden, St. Louis. Pp. 588-590.

Vicente, A.; Ribeiro, A.S.; Santos, E.A. \& Franco, C.R.P. 2005. Levantamento botânico. In: Carvalho, C.M. \& Vilar, J.C. (coords.). Parque Nacional Serra de Itabaiana - levantamento da biota. Ibama, Aracaju. Pp. 15-37. 